\title{
Современные требования \\ к растительным маслам и продуктам их переработки для производства пищевой продукции функционального и специализированного назначения
}

\author{
Зайцева Лариса Валентиновна \\ Всероссийский научно-исследовательский институт кондитерской \\ промышленности - филиал ФГБУН «ФНЦ пищевых систем \\ им. В.М.Горбатова» $Р A H$ \\ Адрес: 107023, Москва, ул. Электрозаводская д. 20, стр. 3 \\ E-mail:lvz2360@mail.ru \\ Мазукабзова Элла Витальевна \\ Всероссийский научно-исследовательский институт кондитерской \\ промышленности - филиал ФГБУН «ФНЦ пищевых систем \\ им. В.М.Горбатова» $Р A H$ \\ Адрес: 107023, Москва, ул. Электрозаводская д. 20, стр. 3 \\ E-mail: conditerprom@mail.ru
}

Матюнина Александра Владимировна

Всероссийский научно-исследовательский институт кондитерской промышленности - филиал ФГБУН «ФНЦ пищевых систем

им. В.М.Горбатова» РАН

Адрес: 107023, Москва, ул. Электрозаводская д. 20, стр. 3

E-mail: conditerprom@mail.ru

Осипов Максим Владимирович

Всероссийский научно-исследовательский институт кондитерской промышленности - филиал ФГБУН «ФНЦ пищевых систем

им. В.М.Горбатова» РАH

Адрес: 107023, Москва, ул. Электрозаводская д. 20, стр. 3

E-mail: conditerprom@mail.ru

\begin{abstract}
В статье рассмотрены различия в требованиях по безопасности, предъявляемых к растительным маслам и продуктам их переработки, используемым при производстве пищевой продукции, в странах Европейского союза и ЕврАзЭс, включая содержание транс-изомеров жирных кислот для заменителей масла какао нетемперируемых нелауринового и лауринового типов, введение ограничений по содержанию канцерогенных и генотоксичных глицидиловых эфиров жирных кислот (в пересчете на глицидол), а также эфиров 3-монохлорпропандиола с жирными кислотами. Для производства пищевой продукции функционального и специализированного назначения рекомендовано использовать растительные масла и продукты их переработки, удовлетворяющие европейским нормативам по содержанию глицидиловых эфиров жирных кислот и эфиров жирных кислот с 3-монохлорпропандиолом. Отдельное внимание уделено повышению пищевой ценности указанной группы продукции за счет внесения жирорастворимых биологически активных веществ, таких как полиненасыщенные жирные кислоты, витамины, антиоксиданты, фитостерины и фосфолипиды. Рассмотрены требования, предъявляемые в странах ЕврАзЭс по обогащению пищевой продукции биологически активными веществами. На основании рекомендаций Всемирной Организации Здравоохранения и результатов исследований, проведенных «Федеральным исследовательским центром питания, биотехнологии и безопасности пищи», сделан вывод о необходимости обогащения пищевой продукции функционального и специализированного назначения, а также пищевой продукции массового потребления такими жирорастворимыми биологически активными
\end{abstract}


веществами, как омега-3 жирные кислоты, витамины D, E, A, каротиноиды. Отмечено, что потребность в этих биологически активных веществах возрастает в период пандемий, включая Covid-19.

Ключевые слова: растительные масла и продукты их переработки, транс-изомеры жирных кислот, глицидиловые эфиры жирных кислот, эфиры 3-монохлорпропандиола с жирными кислотами, жирорастворимые биологически активные вещества

\section{Введение}

В современном мире наблюдаются стремительные изменения в области разработки методов анализа для оценки качества и безопасности пищевой продукции и сырья для ее производства, а также по оценке влияния различных контаминантов на здоровье человека. Причем разрыв между определением вреда контаминанта и введением ограничения по его содержанию быстро сокращается. Изменения в законодательстве требуют быстрого реагирования и со стороны промышленности. В статье рассмотрены новые требования по безопасности к растительным маслам и продуктам их переработки, основанные на современных исследованиях, а также уделено внимание одному из наиболее важных показателей качества, а именно повышению пищевой ценности продукции за счет ее обогащения жирорастворимыми макро- и микронутриентами.

Масла и жиры наряду с белками и углеводами являются основой рациона питания человека и используются при производстве практически всех групп пищевой продукции. Однако, при выпуске пищевой продукции функционального и, тем более специализированного назначения, априори подразумевается, что к ней должны предъявляться повышенные требования по безопасности и пищевой ценности. В статье эти аспекты рассмотрены для растительных масел и продуктов их переработки, используемых при производстве перечисленных групп пищевой продукции.

В соответствие с определением, приведенным в ГОСТ Р 52349-2005': «функциональный пищевой продукт: Специальный пищевой продукт, предназначенный для систематического употребления в составе пищевых рационов всеми возрастными группами здорового населения, обладающий научно обоснованными и подтвержденными свойствами, снижающий риск развития заболеваний, связанных с питанием, предотвращающий дефицит или восполняющий имеющийся в организме человека дефицит питательных веществ, сохраняющий и улучшающий здоровье за счет наличия в его составе функциональных пищевых ингредиентов».

В соответствие с Техническим регламентом ТP TC 027/20112: к специализированной пищевой продукции относится пищевая продукция диетического лечебного и диетического профилактического питания, в том числе для детского питания, а также пищевая продукция для питания спортсменов, беременных и кормящих женщин.

\section{Безопасность}

На основании крупномасштабных популяционных исследований, проведенных в конце XX - начале XXI веков, был признан атерогенный характер транс-изомеров жирных кислот, и доказано их вредное воздействие на здоровье человека, связанное в первую очередь с развитием сердечно-сосудистых и онкологических заболеваний, а также ожирения, сахарного диабета, атеросклероза и целого ряда других заболеваний (Бессонов \& Зайцева, 2016; Зайцева \& Нечаев, 2012). В 2003 году Всемирной Организацией Здравоохранения (ВО3) было рекомендовано снизить потребление транс-изомеров жирных кислот до $1 \%$ от суточной калорийности рациона ${ }^{3}$, а в 2011 году для достижения поставленной цели было рекомендовано ограничить использование частично гидрированных растительных масел при производстве пищевой продукции ${ }^{4}$. Это привело к до-

1 ГОСТ Р 52349-2005. (2006). Продукты пищевые. Продукты пищевые функциональные. Термины и определения. М.: Стандартинформ.

2 ТР ТС 027/2012. (2012). О безопасности отдельных видов специализированной пищевой продукции, в том числе диетического лечебного и диетического профилактического питания. URL: https://docs.cntd.ru/document/902352823 (дата обращения: 05.03.2021).

${ }^{3}$ World Health Organization. (2003). Diet, nutrition and the prevention of chronic disease. Report of Joint WHO/FAO Expert Consultation. Geneva, Swizerland. URL: https://biotech.law.lsu.edu/obesity/who/trs 916.pdf (дата обращения: 11.03.2021).

${ }^{4}$ World Health Organization. (2012). A comprehensive global monitoring framework including indicators and a set of voluntary global targets for prevention and control of noncommunicabale disease. Geneva, Swizerland. URL: http://www.int/nmh/events/2012/discussion peper2_20120322.pdf (дата обращения: 11.03.2021). 
бровольному или законодательному ограничению содержания этих атерогенных веществ в пищевой продукции во многих странах мира (Бессонов \& Зайцева, 2016).

В странах ЕврАзЭс с 1 января 2018 года также вступили в силу требования по ограничению содержания транс-изомеров жирных кислот до 2\% от содержания жира в масложировой продукции (Технический регламент ТР ТС 024/20115). Введение этого норматива не затронуло заменители масла какао нетемперируемые лауринового и нелауринового типов, при производстве последних допускается использование частично гидрированных масел с высоким содержанием транс-изомеров. Изменением 2 в Технический регламент на масложировую продукцию ТР ТС 024/2011 предусматривается введение ограничений по содержанию этих контаминантов не более $2 \%$ (от содержания жира в продукте) в заменителях масла какао лауриновго и нелауринового типов с 01.01.2026 г. С учетом вредного воздействия транс-изомеров на здоровье человека считаем, что в случае функциональной и специализированной продукции (например, при производстве глазированных батончиков, реализуемых через аптечную сеть) необходимо использовать заменители масла какао с содержанием этих контаминантов не более 2 г/100 г, начиная с настоящего времени.

3 марта 2016 года Европейским Агентством по пищевой безопасности (EFSA) было опубликовано научное мнение по исследованию рисков для здоровья человека, обусловленных присутствием в пищевой продукции 3- и 2-монохлорпропандиолов и их эфиров и глицидиловых эфиров жирных кислот (EFSA Panel on Contaminants in the Food Chain, 2016). Оценка рисков производилась по общепринятому в мире протоколу по оценке контаминантов в пищевой цепи (CONTAM Panel). В отчете Объединенного комитета экспертов ФАО/ ВОЗ по пищевым добавкам «Заключение по присутствию определенных примесей в продуктах питания» на основании доклада EFSA был сделан вывод о множественном канцерогенном действии указанных веществ - воздействию в первую очередь подвергались почки и репродуктивная система, кроме того отмечена нейротоксичность и иммунотоксичность. Для глицидиловых эфиров помимо этого установлена генотоксичность - мутации и разрыв нитей ДНК 6 .

Перечисленные контаминанты отсутствуют в нерафинированных растительных маслах. Для образования глицидиловых эфиров жирных кислот необходимы следующие условия: содержание в нерафинированном масле свыше 4\% диацилглицеринов (образуются в условиях длительного и неправильного хранения масличного сырья, их образованию также способствует использование кислых отбельных глин в процессах рафинации) и температура дезодорации свыше $240^{\circ} \mathrm{C}^{7}$.

При высокотемпературной дезодорации (свыше $200^{\circ} \mathrm{C}$ ) также отмечается образование эфиров 3- и 2-монохлорпропандиолов с жирными кислотами. Этот процесс обусловлен взаимодействием диацилглицеринов масел с ионами хлора, присутствующими в используемой в технологическом процессе хлорированной воде. На современном этапе не существует методов эффективного удаления этих контаминантов из конечного продукта. Для ограничения их образования мировым экспертным сообществом разработаны подходы, включающие усовершенствование отдельных стадий очистки растительных масел, а также снижение содержания диацилглицеринов в нерафинированных маслах ${ }^{8}$.

Отчеты Европейского агентства по пищевой безопасности и ВОЗ послужили основанием по законодательному ограничению содержания этих контаминантов в пищевой продукции. В Европейском Союзе Постановлением комиссии (ЕС) $2018 / 290^{9}$ от 26 февраля 2018 года о внесении поправки в регламент (ЕС) № $1881 / 2006^{10}$, наряду с установленными ранее нормативами по содержанию 3-монохлорпропандиола (3-MCPD) в соевом

5 TP TC 024/2011. (2015). Технический регламент на масложировую продукцию. URL: https://docs.cntd.ru/document/902320571 (дата обращения: 15.04.2021).

${ }^{6}$ World Health Organization. (2017). Evaluation of certain contaminants in food: eighty-third report of the Joint FAO/WHO Expert Committee on Food Additives. (2017). Geneva: WHO Press.

7 Там же.

8 Там же.

9 Commission regulation (EU). (2018). No 1881/2006 as regards maximum levels of glycidyl fatty acid esters in vegetable oils and fats, infant formula, follow-on formula and foods for special medical purposes intended for infants and young children. Official Journal of the European Union, 55, 27-29. URL: https://eur-lex.europa.eu/legal-content/EN/TXT/PDF/?uri=CELEX:32018R0290 (дата обращения: 10.03.2020).

${ }^{10}$ Commission regulation (EU). (2020). No 2020/1322 as regards maximum levels of 3-monochloropropanediol (3-MCPD), 3-MCPD fatty acid esters and glycidyl fatty acid esters in certain foods. Official Journal of the European Union, 310, 2-5. URL: https://eur-lex.europa. eu/legal-content/EN/TXT/PDF/?uri=CELEX:32020R1322 \&from=EN (дата обращения: 10.03.2020). 
соусе и гидролизатах растительных белков, были введены нормативы в отношении максимальных уровней содержания глицидиловых эфиров жирных кислот в молочных детских смесях, молочных смесях второго уровня и специализированных лечебных продуктах питания, предназначенных для грудных детей и детей младшего возраста, а также в растительных маслах, как для непосредственного использования в пищу, так и используемых при производстве пищевой продукции. Согласно этому документу содержание глицидиловых эфиров в растительных маслах не должно превышать 1 мг/кг, в случае же их использования при производстве пищевой продукции для грудных детей и детей младшего возраста содержание этих контаминантов не может превышать 0,5 мг/кг.

Для сохранения здоровья населения и гармонизации с международным законодательством 6 августа 2019 года ЕЭК было принято Решение №132 «О внесении изменений в перечень товаров, для которых установлены единые санитарные требования согласно кодам ТН ВЭД ЕАЭС), раздела 1 главы II Единых санитарно-эпидемиологических и гигиенических требований к продукции (товарам), подлежащей санитарно-эпидемиологическому надзору (контролю)». Согласно этому Решению все растительные масла, предназначенные как для непосредственного употребления человеком в пищу, так и в качестве продовольственного (пищевого) сырья, не должны содержать глицидиловых эфиров жирных кислот (в пересчете на глицидол) более 1 мг/кг. Для масел, используемых в производстве продуктов детского питания, этот порог должен быть снижен в 2 раза до 0,5 мг/кг.

Изменением 2 в Технический регламент ТР ТС 024/2011 рассматривается введение нового показателя безопасности для растительных масел. Производители масложировой продукции в настоящее время обсуждают сроки введения норматива по глицидиловым эфирам - для пальмового, пальмоядрового масел и их фракций и кокосового масла с 01.01.2023 года, для остальных масел с 01.01.2025 года.

Проведенные, как в нашей стране, так и за рубежом, исследования жидких растительных масел, включая подсолнечное, рапсовое, соевое, кукурузное, показали, что содержание в них глицидиловых эфиров, как правило, не превышает $1 \mathrm{мг/кг} \mathrm{(EFSA} \mathrm{Panel} \mathrm{on} \mathrm{Contaminants} \mathrm{in} \mathrm{the} \mathrm{Food}$ Chain, 2016; Макаренко, Малинкин, Бессонов, \& Боков, 2020). Наиболее критическая ситуация сложилась с пальмовым маслом рафинированным дезодорированным. Это связано с тем, что в пальмовом масле при длительном хранении плодов масличной пальмы в результате активного протекания липолитических процессов содержание диацилглицеринов может достигать $14 \%$. Это приводит в условиях высокотемпературной дезодорации к экспоненциальному росту содержания глицидиловых эфиров жирных кислот, которое может в конечном рафинированном дезодорированном масле более чем в 10 раз превышать установленный норматив (EFSA Panel on Contaminants in the Food Chain, 2016).

Другими контаминантами, образующимся в процессе дезодорации растительных масел, как уже сказано выше, являются эфиры 3-монохлорпропандиола с жирными кислотами. В 2020 году в Европейском Союзе Постановлением комиссии (EC) 2020/1322 от 23 сентября 2020 года о внесении поправки в регламент (ЕС) № 1881/2006 установлены нормативы содержания 3-монохлорпропандиола и его эфиров с жирными кислотами (в пересчете на 3-монохлорпропандиол) в растительных маслах, как для непосредственного использования в пищу, так и используемых при производстве пищевой продукции (Commission regulation (EU) 2020/1322 of 23 September 2020): для кокосового, кукурузного, рапсового, подсолнечного, соевого, пальмоядрового, оливкового (включая смесь рафинированного масла с маслом холодного отжима) масел и их смесей на уровне не более 1,25 мг/кг; для остальных масел и рыбьих жиров на уровне не более 2,5 мг/кг; для масел, используемых при производстве продуктов для детского питания, этот показатель не должен превышать 0,75 мг/кг. В странах ЕС норматив вступил в силу с 1 января 2021 года. В соответствие с приведенным выше документом продукция, не соответствующая этому нормативу, размещенная на рынке до 1 января 2021 года, может находиться в обороте ограниченное время. В странах ЕврАзЭс вопрос гармонизации с этими нормативами пока только начинает обсуждаться.

Однако для производства пищевой продукции функционального, а тем более специализированного назначения, считаем необходимым использовать растительные масла и продукты их переработки, удовлетворяющие европейским нормативам по содержанию глицидиловых эфиров жирных кислот и эфиров жирных кислот с 3-монохлорпропандиолом.

\section{Повышение пищевой ценности продукции}

Нередко при разработке инновационной пищевой продукции пристальное внимание уделяется 
модификации белковой и/или углеводной составляющих и упускается из виду жировая составляющая, в лучшем случае рассматривается снижение содержания общего жира, а не его состав (Зверев, Карпов, \& Никитина, 2021; Резниченко \& Щеглов, 2020; Zelinkina et al., 2020). При этом жировая составляющая - это не только источник калорий пролонгированного действия, но и источник пластических материалов, необходимых для построения клеток нашего организма. Одним из аспектов качества пищевой продукции в соответствие с Федеральным законом РФ №29-Ф3 «О качестве и безопасности пищевых продуктов» ${ }^{11}$ является ее пищевая ценность и возможность удовлетворения физиологических потребностей человека. В рамках этой статьи хотелось остановиться на повышении пищевой ценности продукции функционального и специализированного назначения за счет использования биологически активных жирорастворимых веществ, в том числе в составе растительных масел и продуктов их переработки.

Существуют определенные нормы по потреблению жиров и отдельных групп жирных кислот при общем снижении калорийности суточного рациона до 2000 ккал/сут (исключение составляют лица, деятельность которых связана с высокими энергозатратами). По результатам последних исследований, проведенных «Федеральным исследовательским центром питания, биотехнологии и безопасности пищи», в зависимости от образа жизни мужчинам рекомендовано потребление жиров 70-135 г/сут, а женщинам - 55-99 г/сут (Тутельян и др., 2020а; Тутельян и др., 2020б). ВОЗ рекомендуется увеличивать в рационе содержание незаменимых полиненасыщенных жирных кислот (ПНЖК) и сокращать содержание насыщенных жирных кислот при строгом ограничении потребления транс-изомеров жирных кислот. Это нашло свое отражение в принятой ВО3 «Глобальной стратегии по питанию, физической активности и здоровью» ${ }^{12}$. В Методических рекомендациях МР 2.3.1.2432-08 ${ }^{13}$ обращается дополнительное внимание на то, что ПНЖК являются не только структурными элементами клеточных мембран, но и обеспечивают нормальное развитие и адаптацию организма человека к неблагоприятным факторам окружающей среды, что очень важно в период пандемий.

При этом отдельно определено оптимальное соотношение в суточном рационе $\omega-6$ к $\omega-3$ жирным кислотам - 5-10:1 ${ }^{14}$. Многими зарубежными исследователями доказано, что снижение этого соотношения до 1-5:1 при общем увеличении потребления полиненасыщенных жирных кислот способствует улучшению метаболизма липидов (Yang et al., 2016; Hammad, Pu, \& Jones, 2016). В РФ имеет место дисбаланс в потреблении различных групп ПНЖК, а именно переизбыток в пищевом рационе омега-6 жирных кислот при дефиците омега-3 жирных кислот. Дефицит омега-3 жирных кислот отмечается и во многих странах мира, что приводит к возникновению основных неинфекционных заболеваний современности - сердечно-сосудистых и онкологических, ожирения и сахарного диабета, а также воспалительных процессов и многое другое (Зайцева \& Нечаев, 2014). В связи с этим считаем необходимым обогащение омега-3 жирными кислотами не только пищевой продукции функционального и специализированного назначения, но и продукции массового потребления (молочной, хлебобулочной, масложировой, кондитерской продукции).

Наилучшим вариантом обогащения пищевой продукции этими незаменимыми веществами является использование в рецептуре жирового компонента, содержащего омега-3 жирные кислоты. В соответствие с Техническим регламентом ТP ТС 022/2011 $1^{15}$ среди отечественных растительных масел высокое содержание альфа-линоленовой кислоты отмечается в рапсовом, соевом, горчичном и, особенно, в льняном и рыжиковом маслах - более 2,4 г/100 г (мл) растительных масел ${ }^{16}$. Источником длинноцепочечных омега-3 жирных кислот (эйкозопентаеновой и докозогексаеновой) являются жиры рыб. Однако при обогащении пищевой продукции ПНЖК необходимо помнить о том, что они подвержены пероксидному окислению с образованием опасных

${ }^{11}$ Ф3 «О качестве и безопасности пищевых продуктов». (2000). URL: http://www.consultant.ru/document/cons_doc_LAW_25584/ (дата обращения: 13.04.2021).

${ }^{12}$ Global strategy on diet, physical activity and health. (2004). URL: www.who.int/dietphysicalactivity/strategy/eb11344/strategy_ english_web.pdf (дата обращения: 11.04.2021).

${ }^{13}$ MP 2.3.1.2432-08. (2008). Нормы физиологических потребностей в энергии и пищевых веществах для различных групп населения Российской Федерации. URL: https://docs.cntd.ru/document/1200076084 (дата обращения: 12.03.2021).

${ }_{14}^{14}$ Там же.

15 TP TC 022/2011. (2018). Пищевая продукция в части ее маркировки. URL: https://docs.cntd.ru/document/902320347 (дата обращения: 10.03.2021).

${ }^{16}$ Codex Stan 210.(2003).Codex standard for named vegetable oils URL: http://www.justice.gov.md/file/Centrul\%20de\%20armonizare\%20 a\%20legislatiei/Baza\%20de\%20date/Materiale\%202008/Legislatie/Codex\%20STAN\%20210.PDF (дата обращения: 13.04.2021). 
для здоровья первичных и вторичных продуктов окисления. Для сохранения ПНЖК в пищевой продукции помимо использования антиоксидантов рассматриваются также и другие стратегии, включающие оптимизацию параметров и условий внесения этих кислот в пищевой продукт, а также транспортных систем для их утилизации организмом (Jacobsen, 2015).

Масложировые ингредиенты также могут стать источником других биологически активных веществ: жирорастворимых витаминов A, D, E, каротиноидов, фитостеринов, фосфолипидов. Роль этих веществ в питании человека уже доказана и определены физиологические нормы их потребления (Тутельян и др., 2020а). В РФ в питании, как взрослого населения, так и детей, отмечается дефицит в потреблении целого рядов витаминов, включая жирорастворимые. Исследования, проведенные ФГБУН «ФИЦ питания и биотехнологии», свидетельствуют о наличии дефицита витамина D у всего населения РФ, у детей кроме этого отмечается дефицит жирорастворимых антиоксидантов, таких как токоферолы и $\beta$-каротин, девочки с ожирением также хуже обеспечены витамином А (Бекетова и др., 2019; Коденцова, Вржесинская, Никитюк, \& Тутельян, 2018).

Роль витамина D в организме человека долгое время воспринималась очень узко - нормальное развитие костной ткани и предотвращение остеопорозов и переломов. Сейчас доказана его роль в предотвращении сердечных приступов и укреплении сосудов, в лечении многих форм рака (груди, почек, толстой кишки, поджелудочной железы), диабета 1 типа, гипертензии, воспалительных процессов, и многое другое (Коденцова и др., 2017; Кинаш \& Боярчук, 2020). Обсуждается возможная взаимосвязь с тяжелым протеканием короновирусной инфекции и дефицитом в организме витамина D (Тутельян и др., 2020б). Норма потребления витамина D составляет 15 мкг/ сутки (MP 2.3.1.2432-08). Биологическая активность витамина $\mathrm{D}_{3}$ (холекальциферол) для человека несколько выше, чем $\mathrm{D}_{2}$ (эргокальциферол), поэтому целесообразно использовать эту форму для обогащения пищевой продукции (Коденцова и др., 2017). Потребность в пищевой продукции, обогащенной витамином D, как отмечено выше, возрастает в период пандемий, включая Covid-19.
Немаловажным фактором, влияющим на иммунитет в период пандемии новой коронавирусной инфекции COVID-19, является обеспеченность также витаминами Е и А, играющими важную роль в повышении иммунитета организма (Тутельян и др., 2020a).

Витамин Е представляет собой смесь токоферолов и токотриенолов, обладающих помимо витаминной также антиоксидантной активностью. Эти вещества участвуют в предотвращении развития сердечно-сосудистых заболеваний, способствуют укреплению иммунной системы. У отдельных изомеров токотриенолов, содержащихся в пальмовом масле, выявлена антиканцерогенная активность (Abu-Fayyad \& Nazzal, 2017). Ежедневное потребление токоферолов и токотриенолов снижает риск развития ишемической болезни сердца, инфаркта миокарда, инсульта, улучшает общее состояние и функции сердечно-сосудистой и центральной нервной систем, инсулинзависимого сахарного диабета (Медведев, Иванова, \& Медведева, 2018; Кинаш \& Боярчук, 2020). Рекомендуемая норма потребления витамина Е составляет 15 мг/сут (MP 2.3.1.2432-08). Токоферолы также препятствуют окислительной порче масложировых продуктов, приводящей к образованию токсичных соединений (Marmesat, Morales, Ruiz-Mendez, Marquez-Ruiz, \& Velasco, 2016).

Витамин А играет важную роль в процессах роста и репродукции, дифференцировки эпителиальной и костной ткани, поддержании зрения (Кинаш \& Боярчук, 2020). Он также участвует в поддержании иммунитета и повышении устойчивости к инфекциям, что усиливает его функции в организме в период пандемий. Достаточным является потребление витамина А в количествен не менее 900 мкг рет. экв./сутки (МР 2.3.1.2432-08).

Хорошо изучено противовоспалительное действие и влияние таких антиоксидантов, как каротиноиды, особенно бета-каротина и ликопина, на сердечно-сосудистую и иммунную системы (Кинаш \& Боярчук, 2020). Суточная норма их потребления составляет 5 мг/сутки (MP 2.3.1.2432-08 ${ }^{17}$; MP 2.3.1.1915$\left.04^{18}\right)$. Потребность в повышенном потреблении антиоксидантов возрастает в период пандемий.

Таким образом, в настоящее время возрастает потребность в обеспечении населения пищевой про-

${ }^{17}$ MP 2.3.1.2432-08. (2009). Нормы физиологических потребностей в энергии и пищевых веществах для различных групп населения Российской Федерации. URL: https://rospotrebnadzor.ru/documents/details.php?ELEMENT_ID=4583 (дата обращения: 12.03.2021).

${ }^{18}$ MP 2.3.1.1915-04. (2004). Рекомендуемые уровни потребления пищевых и биологически активных веществ. URL: https://docs. cntd.ru/document/1200037560 (дата обращения: 12.03.2021). 
дукцией, обогащенной этими жирорастворимыми биологически активными веществами (Коденцова \& Вржесинская, 2016), и особенно это относится к пищевой продукции функционального и специализированного назначения. При витаминизации пищевой продукции несколькими витаминами необходимо учитывать характер их взаимодействий не только с компонентами продукта, но и друг с другом (Коденцова, Жилинская, \& Шпигель, 2020). В случае отсутствия необходимости в проведении клинических испытаний (для функциональной продукции) при обогащении изделия несколькими витаминами лучше не превышать их содержания на уровне «источник» (Технический регламент ТР ТС 022/2011 ${ }^{19}$ ) или применять готовые мультивитаминные комлексы, разрешенные для использования при производстве пищевой продукции.

Представляет интерес также обогащение пищевой продукции фитостеринами. Они существенно снижают уровень свободного холестерина в липопротеидах низкой плотности, способны вытеснять холестерин из мембранных структур. Рекомендуемый уровень потребления растительных стеринов (фитостеринов) для взрослых составляет 300 мг/ сутки (MP 2.3.1.2432-08). При обогащении пищевой продукции фитостеринами необходимо учитывать подвергается ли пищевая продукция термообработке в процессе ее производства или дальнейшего использования, это касается в частности маргаринов. При нагревании продукции, обогащенной фитостеринами, происходит образование окисленных форм фитостеринов, а целым рядом исследований показано, что их воздействие на организм человека сходно с воздействием окисленных форм холестерина (Lin \& Trautwein, 2016).

Фосфолипиды обеспечивают необходимую текучесть и гибкость мембран и их барьерные свойства; растворяют неметаболизированный холестерин; служат профилактикой сердечно-сосудистых заболеваний (особенно атеросклероза); способствуют правильному сворачиванию крови и ее циркуляции; необходимы для нормального функционирования нервной системы, органов пищеварения, печени; повышают чувствительность к инсулину. Норма их потребления 5-7 г/сутки (MP 2.3.1.2432-08). Чаще всего для целей обогащения пищевой продукции используют соевый лецитин или лецитин яичного белка.
Для равномерного распределения жирорастворимых биологически активных веществ в конечной продукции лучше всего их вносить в составе жировой фазы. В соответствие с действующим законодательством определены два уровня обогащения пищевой продукции - «источник» и «высокое содержание» (Технический регламент ТР ТС 022/2011):

источником омега-3 жирных кислот, если их сумма составляет не менее 0,2 г на 100 г для твердой пищевой продукции или для жидкостей на 100 мл, а для жиров и масел растительных или животных сумма омега-3 жирных кислот составляет не менее 1,2 г на 100 г для твердой пищевой продукции или для жидкостей на 100 мл;

- с высоким содержанием омега-3 жирных кислот, если их сумма составляет не менее 0,4 г на 100 г для твердой пищевой продукции или для жидкостей на 100 мл, а для жиров и масел растительных или животных сумма омега-3 жирных кислот составляет не менее 2,4 г на 100 г для твердой пищевой продукции или для жидкостей на 100 мл;

источником витаминов, если их содержание составляет не менее 15 процентов средней суточной потребности взрослого человека в витаминах на 100 г твердой пищевой продукции или 7,5 процентов для жидкостей на 100 мл либо на одну порцию;

с высоким содержанием витаминов, если их содержание составляет не менее 30 процентов средней суточной потребности взрослого человека в витаминах на 100 г для твердой пищевой продукции или для жидкостей на 100 мл либо на одну порцию.

Для обогащенной высококалорийной пищевой продукции (350 ккал/100 г и более) расчет витаминов в соответствие с СанПиН 2.3.2.2804-10 ${ }^{20}$ (п.8.3.1) необходимо вести на одну стандартную порцию или на 100 ккал.

\section{Выводы}

При выборе сырья для производства пищевой продукции функционального и специализированного назначения с содержанием жировой фазы более 3 г/ 100 г необходимо учитывать со-

19 TP TC 022/2011. Пищевая продукция в части ее маркировки. URL: https://docs.cntd.ru/document/902320347 (дата обращения: 12.03.2021).

${ }^{20}$ СанПиН 2.3.2.2804-10. (2010). Гигиенические требования безопасности и пищевой ценности продукции. URL: https://docs.cntd. ru/document/902256292 (дата обращения: 10.04.2021). 
временные рекомендации по нормам безопасности к растительным маслам и жирам и продуктам их переработки с настоящего времени, основываясь на опыте и законодательной базе стран Европейского Союза:

- содержание транс-изомеров жирных кислот не должно превышать $2 \%$ от содержания жира в продукте;

- содержание глицидиловых эфиров не должно превышать 1 мг/кг, а при производстве пищевой продукции для грудных детей и детей младшего возраста - не более 0,5 мг/кг;

- содержания 3-монохлорпропандиола и его эфиров с жирными кислотами для кокосового, кукурузного, рапсового, подсолнечного, соевого, пальмоядрового, оливкового (включая смесь рафинированного масла с маслом холодного отжима) масел и их смесей не должно превышать 1,25 мг/кг; для остальных масел и рыбьих жиров - не более 2,5 мг/кг; для масел, используемых при производстве продуктов для детского питания - не более $0,75 \mathrm{Mг} / \mathrm{кг.}$

Учитывая дефицит ПНЖК класса омега-3 и витамина D практически у всех групп населения РФ, a также возрастающую потребность в витаминах D, A, Е и каротиноидах в период пандемий, считаем необходимым сосредоточить усилия производителей на обогащении продукции функционального и специализированного назначения этими жирорастворимыми биологически активными веществами, с последующим охватом продукции массового потребления.

\section{Литература}

Бекетова, Н. А., Павловская, Е. В., Коденцова, В. М., Вржесинская, О. А., Кошелева, О. В., Сокольников, А. А., \& Строкова, Т. В. (2019). Обеспеченность витаминами детей школьного возраста с ожирением. Вопросы питания, 88(4), 66-74. https://doi.org/10.24411/0042-8833-2019-10043

Бессонов, В. В., \& Зайцева, Л. В. (2016). Трансизомеры жирных кислот: риски для здоровья и пути снижения потребления. Вопросы питания, 85(3), 6-17.

Зайцева Л. В., \& Нечаев А.П. (2012). Биохимические аспекты потребления транс-изомеров жирных кислот. Вопросы диетологии, 4(2), 17-23.

Зайцева, Л. В., \& Нечаев, А. П. (2014). Полиненасыщенные жирные кислоты в питании: Современный взгляд. Пищевая промышленность, 4, 14-19.
Зверев, С. В., Карпов, В. И., \& Никитина, М. А. (2021). Оптимизация пищевых композиций по профилю идеального белка. Пищевые системы, 4(1), 4-11. https://doi.org/10.21323/2618-9771-2021-4-1-4-11

Кинаш, М. И., \& Боярчук, О. Р. (2020). Жирорастворимые витамины и иммунодефицитные состояния: механизмы влияния и возможности использования. Вопросы питания, 89(3), 22-32. https://doi.org/10.24411/0042-8833-2020-10026

Коденцова, В. М., \& Вржесинская, О. А. (2016). Анализ отечественного и международного опыта использования обогащенных витаминами пищевых продуктов. Вопросы питания, 2, 31-50.

Коденцова, В. М., Мендель, О. И., Хотимченко, С. А., Батурин, А. К., Никитюк, Д. Б., \& Тутельян, В. А. (2017). Физиологическая потребность и эффективные дозы витамина D для коррекции его дефицита. Современное состояние проблемы. Вопросы питания, 86(2), 47-62. https://doi. org/10.24411/0042-8833-2017-00033

Коденцова, В. М., Вржесинская, О. А., Никитюк, Д. Б., \& Тутельян, В. А. (2018). Витаминная обеспеченность взрослого населения Российской Федерации: 1987-2017 гг. Bопросы питания, 87(4), 62-68. https://doi. org/10.24411/0042-8833-2018-10043

Коденцова, В. М., Жилинская, Н. В., \& Шпигель, Б. И. (2020). Витаминология: от молекулярных аспектов к технологиям витаминизации детского и взрослого населения. Bопросы питания, 89(4), 89-99. https://doi. org/10.24411/0042-8833-2020-10045

Макаренко, М. А., Малинкин, А. Д., Бессонов, В. В., \& Боков, Д. О. (2020). Определение эфиров монохлорпропандиола и глицидиловых эфиров методом длительной щелочной переэтерификации с газовой хроматографией с тандемным масс-спектрометрическим детектированием в пищевых растительных маслах и масложировых продуктах. Вопросы питания, 89(6), 113122. https://doi.org/10.24411/0042-8833-202010084

Медведев, О. С., Иванова, А. Ю., \& Медведева, Н. А. (2018). Биологические свойства токотриенолов. Вопросы питания, 87(2), 5-16. https://doi. org/10.24411/0042-8833-2018-10013

Резниченко, И. Ю., \& Щеглов, М. С. (2020). Сахарозаменители и подсластители в технологии кондитерских изделий. Техника и технология пищевых производств, 4, 576-587. https://doi. org/10.21603/2074-9414-2020-4-576-587

Тутельян, В. А., Никитюк, Д. Б., Бурляева, Е. А., Хотимченко, С. А., Батурин, А. К., Стародубова, А. В., Камбаров, А. О., Шевелева, С. А., \& Жилинская, Н. В. (2020а). COVID-19: Новые вызовы для медицинской науки и практического 
здравоохранения. Вопросы питания, 89(3), 6-13. https://doi.org/10.24411/0042-8833-2020-10024

Тутельян, В. А., Никитюк, Д. Б., Батурин, А. К., Васильев, А. В., Гаппаров, М. М. Г., Жилинская, Н. В., Жминченко, В. М., Камбаров, А. О., Коденцова, В. М., Кравченко, Л. В., Кулакова, С. Н., Лашнева, Н. В., Мазо, В. К., Соколов, А. И., Суханов, Б. П., \& Хотимченко, С. А. (2020б). Нутриом как направление «главного удара»: Определение физиологических потребностей в макро- и микронутриентах, минорных биологически активных веществах пищи. Вопросы питания, 89(4), 24-34. https://doi. org/10.24411/0042-8833-2020-10039

Abu-Fayyad, A., \& Nazzal, S. (2017). Extraction of vitamin $\mathrm{E}$ isomers from palm oil: methodology, characterization, and in vitro anti-tumor activity. Journal of the American Oil Chemists' Society, 94(9), 1209-1217. https://doi.org/10.1007/s11746-0173025-8

Hammad, S., Pu, S., \& Jones, P. J. (2016). Current evidence supporting the link between dietary fatty acids and cardiovascular disease. Lipids, 51(5), 507-517. https://doi.org/10.1007/s11745-0154113-x

Jacobsen, C. (2015). Some strategies for the stabilization of long chain n-3 PUFA-enriched foods: A review. European Journal of Lipid Science and Technology, 117(11), 1853-1866. https://doi. org/10.1002/ejlt.201500137

Lin, Y., Knol, D., \& Trautwein, E. A. (2016). Phytosterol oxidation products (POP) in foods with added phytosterols and estimation of their daily intake: A literature review. European Journal of Lipid Science and Technology, 118(10), 1423-1438. https://doi.org/10.1002/ejlt.201500368

Marmesat, S., Morales, A., Ruiz-Mendez, M. V., Marquez-Ruiz, G., \& Velasco J. (2016). Inhibition of hydroperoxy-, keto- and hydroxy-FAME by alpha- and delta-tocopherol at rancimat conditions. Journal of the American Oil Chemists' Society, 93(1), 93-103. https://doi.org/10.1007/ s11746-015-2748-7

EFSA Panel on Contaminants in the Food Chain (CONTAM). (2016). Scientific opinion Risks for human health related to the presence of 3- and 2-monochloropropanediol (MCPD), and their fatty acid esters, and glycidyl fatty acid esters in food. EFSA Journal, 17(5), 1-159. https://doi. org/10.2903/j.efsa.2016.4426

Yang, L. G., Song, Z. X., Yin, H., Wang, Y. Y., Shu, G. F., Lu, H. X., Wang, S. K., \& Sun, G. J. (2016). Low n-6/n-3 PUFA ratio improves lipid metabolism, inflammation, oxidative stress and endothelial function in rats using plant oils as n-3 fatty acids source. Lipids, 51(1), 49-59. https://doi. org/10.1007/s11745-015-4091-z

Zelikina, D. V., Gureeva, M. D., Chebotarev, S. A., Samuseva, Yu. V., Antipova, A. S., Martirosova, E. I., \& Semenova, M. G. (2020). Functional food compositions based on whey protein isolate, fish oil and soy phospholipids. Пищевые системы, 3(1), 16-20. https://doi.org/10.21323/2618-9771-20203-1-16-20 


\title{
Modern Requirements for Vegetable Oils and their Processed Products Used in Functional and Specialized Food Products
}

\author{
Larisa V. Zaitseva \\ All-Russia Research Institute of the Confectionery Industry - \\ branch of V.M. Gorbatov Federal Research Center \\ for Food Systems of Russian Academy of Science
} building 3, 20, Elektrozavodskaya str., Moscow, 107023, Russian Federation E-mail:lvz2360@mail.ru

Ella V. Mazukabzova All-Russia Research Institute of the Confectionery Industry branch of V.M. Gorbatov Federal Research Center for Food Systems of Russian Academy of Science building 3, 20, Elektrozavodskaya str., Moscow, 107023, Russian Federation E-mail: conditerprom@mail.ru

\author{
Alexandra V. Matunina \\ All-Russia Research Institute of the Confectionery Industry - \\ branch of V.M. Gorbatov Federal Research Center \\ for Food Systems of Russian Academy of Science \\ building 3, 20, Elektrozavodskaya str., Moscow, 107023, Russian Federation \\ E-mail:conditerprom@mail.ru \\ Maxim V. Osipov \\ All-Russia Research Institute of the Confectionery Industry - \\ branch of V.M. Gorbatov Federal Research Center \\ for Food Systems of Russian Academy of Science \\ building 3, 20, Elektrozavodskaya str., Moscow, 107023, Russian Federation \\ E-mail: conditerprom@mail.ru
}

\begin{abstract}
The new safety standards for vegetable oils and their processing products used in the manufacture of food products in the countries of the European Union and EurAsEC have been discussed in this article, including changes in the permissible level of trans-isomers of fatty acids for cocoa butter substitutes of non-lauric and lauric types, the introduction of restrictions on the content of carcinogenic and genotoxic glycidyl esters of fatty acids (in terms of glycidol), as well as esters of 3-monochloropropanediol with fatty acids. For the production of functional and specialized food products, it is recommended to use vegetable oils and their processed products that meet the European standards for the content of glycidyl esters of fatty acids and fatty acid esters of 3-monochloropropanediol. Special attention is paid to increasing the nutritional value of this group of products due to fat-soluble biologically active substances, such as polyunsaturated fatty acids, vitamins, antioxidants, phytosterols and phospholipids.The requirements for the enrichment of food products with biologically active substances in the EurAsEC countries are considered. Based on the recommendations of the World Health Organization and the results of research conducted by the Federal Research Center for Nutrition, Biotechnology and Food Safety, it is concluded that it is necessary to enrich functional and specialized food products, as well as food products of mass consumption with such fat-soluble biologically active substances as omega-3 fatty acids, vitamins D, E, A, carotenoids. It is noted that the need for these biologically active substances increases during pandemics, including Covid-19.
\end{abstract}

Keywords: vegetable oils and its processed products, trans-isomers of fatty acids, glycidyl fatty acid esters, fatty acid esters of 3-monochloropropanediol, fat-soluble biologically active substances 


\section{References}

Beketova, N. A., Pavlovskaya, E. V., Kodentsova, V. M., Vrzhesinskaya, O. A., Kosheleva, O. V., Sokol'nikov, A. A., \& Strokova, T. V. (2019). Obespechennost' vitaminami detei shkol'nogo vozrasta s ozhireniem [Biomarkers of vitamin status in obese school children]. Voprosy pitaniya [Problems of Nutrition], 88(4), 66-74. https://doi.org/10.24411/0042-8833-201910043

Bessonov, V. V., \& Zaitseva, L. V. (2016). Transizomery zhirnykh kislot: riski dlya zdorov'ya i puti snizheniya potrebleniya [Transisomers of fatty acids: health risks and ways to reduce consumption]. Voprosy pitaniya [Problems of Nutrition], 85(3), 6-17.

Zaitseva L.V., Nechaev A.P. (2012). Biokhimicheskie aspekty potrebleniya trans-izomerov zhirnykh kislot [Biochemical aspects of consumption of trans-isomer fatty acids]. Voprosy dietologii [Nutrinion], 4(2), 17-23.

Zaitseva, L. V., \& Nechaev, A. P. (2014). Polinenasyshchennye zhirnye kisloty $\mathrm{v}$ pitanii: Sovremennyi vzglyad [Polyunsaturated Fatty Acids in the Nutrition: Modern View]. Pishchevaya promyshlennost' [Food processing Industry], 4, 14-19.

Zverev, S. V., Karpov, V. I., \& Nikitina, M. A. (2021). Optimizatsiya pishchevykh kompozitsii po profilyu ideal'nogo belka [Optimization of food compositions according to the ideal protein profile]. Pishchevye sistemy [Food Systems], 4(1), 4-11. https:// doi.org/10.21323/2618-9771-2021-4-1-4-11

Kinash, M. I., \& Boyarchuk, O. R. (2020). Zhirorastvorimye vitaminy i immunodefitsitnye sostoyaniya: mekhanizmy vliyaniya i vozmozhnosti ispol'zovaniya [Fat-soluble vitamins and immunodeficiency: mechanisms of influence and opportunities for use]. Voprosy pitaniya [Problems of Nutrition], 89(3), 22-32. https://doi.org/10.24411/0042-8833-2020-10026

Kodentsova, V. M., \& Vrzhesinskaya, O. A. (2016). Analiz otechestvennogo i mezhdunarodnogo opyta ispol'zovaniya obogashchennykh vitaminami pishchevykh produktov [Analysis of domestic and international experience in the use of vitamin-rich foods]. Voprosy pitaniya [Problems of Nutrition], 2, 31-50.

Kodentsova, V. M., Mendel', O. I., Khotimchenko, S. A., Baturin, A. K., Nikityuk, D. B., \& Tutel'yan, V. A. (2017). Fiziologicheskaya potrebnost' i effektivnye dozy vitamina D dlya korrektsii ego defitsita. Sovremennoe sostoyanie problem [Physiological needs and effective doses of vitamin $\mathrm{D}$ for deficiency correction. Current state of the problem]. Voprosy pitaniya [Problems of Nutrition], 86(2), 47-62. https://doi.org/10.24411/0042-8833-2017-00033

Kodentsova, V. M., Vrzhesinskaya, O. A., Nikityuk, D. B., \& Tutel'yan, V. A. (2018). Vitaminnaya obespechennost' vzroslogo naseleniya Rossiiskoi Federatsii: 1987-2017 gg [Vitamin status of adult population of the Russian Federation: 1987-2017]. Voprosy pitaniya [Problems of Nutrition], 87(4), 62-68. https://doi.org/10.24411/0042-8833-2018-10043

Kodentsova, V. M., Zhilinskaya, N. V., \& Shpigel', B. I. (2020). Vitaminologiya: ot molekulyarnykh aspektov $\mathrm{k}$ tekhnologiyam vitaminizatsii detskogo i vzroslogo naseleniya [Vitaminology: from molecular aspects to improving technology of vitamin status children and adults]. Voprosy pitaniya [Problems of Nutrition], 89(4), 89-99. https://doi. org/10.24411/0042-8833-2020-10045

Makarenko, M. A., Malinkin, A. D., Bessonov, V. V., \& Bokov, D. O. (2020). Opredelenie efirov monokhlorpropandiola i glitsidilovykh efirov metodom dlitel'noi shchelochnoi pereeterifikatsii s gazovoi khromatografiei s tandemnym mass-spektrometricheskim detektirovaniem $\mathrm{v}$ pishchevykh rastitel'nykh maslakh i maslozhirovykh produktakh [Alkaline transesterification CG-MS/MS method of monochlorpropanediol and glycidyl esters' determination in some edible fats, oils and fat blends on Russian market]. Voprosy pitaniya [Problems of Nutrition], 89(6), 113-122. https://doi. org/10.24411/0042-8833-2020-10084

Medvedev, O. S., Ivanova, A. Yu., \& Medvedeva, N. A. (2018). Biologicheskie svoistva tokotrienolov [Biological properties of tocotrienols]. Voprosy pitaniya [Problems of Nutrition], 87(2), 5-16. https:// doi.org/10.24411/0042-8833-2018-10013

Reznichenko, I. Yu., \& Shcheglov, M. S. (2020). Sakharozameniteli i podslastiteli v tekhnologii konditerskikh izdelii [Sugar substitutes and sweeteners in confectionery technology]. Tekhnika i tekhnologiya pishchevykh proizvodstv [Food Processing: Techniques and Technology], 4, 576-587. https://doi. org/10.21603/2074-9414-2020-4-576-587

Tutel'yan, V. A., Nikityuk, D. B., Burlyaeva, E. A., Khotimchenko, S. A., Baturin, A. K., Starodubova, A. V., Kambarov, A. O., Sheveleva, S. A., \& Zhilinskaya, N. V. (2020a). COVID-19: Novye vyzovy dlya meditsinskoi nauki i prakticheskogo zdravookhraneniya [COVID-19: New Challenges for Medical Science and Practical Health]. Voprosy pitaniya [Problems of Nutrition], 89(3), 6-13. https://doi.org/10.24411/0042-8833-2020-10024

Tutel'yan, V. A., Nikityuk, D. B., Baturin, A. K., Vasil'ev, A. V., Gapparov, M. M. G., Zhilinskaya, N. V., Zhminchenko, V. M., Kambarov, A. O., Kodentsova, V. M., Kravchenko, L. V., Kulakova, S. N., Lashneva, N. V., Mazo, V. K., Sokolov, A. I., Sukhanov, B. P., \& Khotimchenko, S. A. (2020b). Nutriom kak napravlenie «glavnogo udara»: Opredelenie fiziologicheskikh potrebnostei v makro- i mikronutrientakh, minornykh biologiches- 
ki aktivnykh veshchestvakh pishchi [Nutriome as the direction of the "main blow": determination of physiological needs in macro- and micronutrients, minor biologically active substances]. Voprosy pitaniya [Problems of Nutrition], 89(4), 24-34. https:// doi.org/10.24411/0042-8833-2020-10039

Abu-Fayyad, A., \& Nazzal, S. (2017). Extraction of vitamin E isomers from palm oil: methodology, characterization, and in vitro anti-tumor activity. Journal of the American Oil Chemists' Society, 94(9), 12091217. https://doi.org/10.1007/s11746-017-3025-8

Hammad, S., Pu, S., \& Jones, P. J. (2016). Current evidence supporting the link between dietary fatty acids and cardiovascular disease. Lipids, 51(5), 507517. https://doi.org/10.1007/s11745-015-4113-X

Jacobsen, C. (2015). Some strategies for the stabilization of long chain n-3 PUFA-enriched foods: A review. European Journal of Lipid Science and Technology, 117(11), 1853-1866. https://doi. org/10.1002/ejlt.201500137

Lin, Y., Knol, D., \& Trautwein, E. A. (2016). Phytosterol oxidation products (POP) in foods with added phytosterols and estimation of their daily intake: A literature review. European Journal of Lipid Science and Technology, 118(10), 1423-1438. https://doi.org/10.1002/ejlt.201500368
Marmesat, S., Morales, A., Ruiz-Mendez, M. V., Marquez-Ruiz, G., \& Velasco J. (2016). Inhibition of hydroperoxy-, keto- and hydroxy-FAME by alpha- and delta-tocopherol at rancimat conditions. Journal of the American Oil Chemists' Society, 93(1), 93-103. https://doi.org/10.1007/s11746-0152748-7

EFSA Panel on Contaminants in the Food Chain (CONTAM). (2016). Scientific opinion Risks for human health related to the presence of 3- and 2-monochloropropanediol (MCPD), and their fatty acid esters, and glycidyl fatty acid esters in food. EFSA Journal, 17(5), 1-159. https://doi. org/10.2903/j.efsa.2016.4426

Yang, L. G., Song, Z. X., Yin, H., Wang, Y. Y., Shu, G. F., Lu, H. X., Wang, S. K., \& Sun, G. J. (2016). Low n-6/n-3 PUFA ratio improves lipid metabolism, inflammation, oxidative stress and endothelial function in rats using plant oils as n-3 fatty acids source. Lipids, 51(1), 49-59. https://doi. org/10.1007/s11745-015-4091-z

Zelikina, D. V., Gureeva, M. D., Chebotarev, S. A., Samuseva, Yu. V., Antipova, A. S., Martirosova, E. I., \& Semenova, M. G. (2020). Functional food compositions based on whey protein isolate, fish oil and soy phospholipids. 